\title{
COUPLED FIXED POINTS OF MONOTONE MAPPINGS IN A METRIC SPACE WITH A GRAPH
}

\author{
MONTHER RASHED ALFURAIDAN* AND MOHAMED AMINE KHAMSI** \\ *Department of Mathematics \& Statistics \\ King Fahd University of Petroleum and Minerals \\ Dhahran 31261, Saudi Arabia \\ E-mail: monther@kfupm.edu.sa \\ **Department of Mathematical Sciences \\ University of Texas at El Paso \\ El Paso, TX 79968, USA \\ E-mail: mohamed@utep.edu
}

\begin{abstract}
In this work, we define the concept of mixed $G$-monotone mappings defined on a metric space endowed with a graph. Then we obtain sufficient conditions for the existence of coupled fixed points for such mappings when a weak contractivity type condition is satisfied.

Key Words and Phrases: Directed graph, coupled fixed point, mixed monotone mapping, multivalued mapping.
\end{abstract}

2010 Mathematics Subject Classification: 47H09, 6B20, 47H10, 47E10.

Acknowledgements. The authors would like to acknowledge the support provided by the Deanship of Scientific Research at King Fahd University of Petroleum \& Minerals for funding this work through project No. IP142-MATH-111.

\section{REFERENCES}

[1] M.R. Alfuraidan, Remarks on monotone multivalued mappings on a metric space with a graph, J. Ineq. Appl., 202(2015).

[2] I. Beg, A.R. Butt, Fixed point for set valued mappings satisfying an implicit relation in partially ordered metric spaces, Nonlinear Anal., 71(2009), 3699-3704.

[3] T.G. Bhaskar, V. Lakshmikantham, Fixed point theory in partially ordered metric spaces and applications, Nonlinear Anal., 65(2006), 1379-1393.

[4] Z. Drici, F.A. McRae, J.V. Devi, Fixed point theorems in partially ordered metric space for operators with PPF dependence, Nonlinear Anal., 67(2007), 641-647.

[5] D. Guo, Fixed points of mixed monotone operators with application, Appl. Anal., 34(1988), 215-224.

[6] D. Guo, V. Lakskmikantham, Coupled fixed points of nonlinear operators with applications, Nonlinear Anal., 11(5)(1987), 623-632.

[7] J. Harjani, K. Sadarangani, Generalized contractions in partially ordered metric spaces and applications to ordinary differential equations, Nonlinear Anal., 72(2010), 1188-1197.

[8] J. Jachymski, The contraction principle for mappings on a metric space with a graph, Proc. Amer. Math. Soc., 1(136)(2008), 1359-1373. 
[9] J. Jachymski, G.G. Lukawska, IFS on a metric space with a graph structure and extension of the Kelisky-Rivlin theorem, J. Math. Anal. Appl., 356(2009), 453-463.

[10] S.B. Nadler, Multivalued contraction mappings, Pacific J. Math., 30(1969), 475-488.

[11] J.J. Nieto, R.L. Pouso, R. Rodriguez-Lopez, Fixed point theorems in ordered abstract spaces, Proc. Amer. Math. Soc., 135(2007), 2505-2517.

[12] D. O'Regan, A. Petruşel, Fixed point theorems for generalized contraction in ordered metric spaces, J. Math. Anal. Appl., 341(2008), 1241-1252.

[13] A. Petruşel, I.A. Rus, Fixed point theorems in ordered L-spaces, Proc. Amer. Math. Soc., 134(2005), 411-418

[14] A.C.M. Ran, M.C.B. Reurings, A fixed point theorem in partially ordered sets and some applications to matrix equations, Proc. Amer. Math. Soc., 132(2003), 1435-1443.

[15] C. Zhai, Fixed point theorems for a class of mixed monotone operators with convexity, Fixed Point Theory Appl., 2013:119, (2013).

Received: January 14, 2016; Accepted: July 28, 2016. 
